\title{
Originals
}

\section{Potential use of glutathione for the prevention and treatment of diabetic neuropathy in the streptozotocin-induced diabetic rat}

\author{
B. Bravenboer ${ }^{1}$, A. C. Kappelle ${ }^{2}$, F. P. T.Hamers ${ }^{2}$, T. van Buren ${ }^{2}$, D. W. Erkelens ${ }^{1}$ and W.H. Gispen ${ }^{2}$ \\ ${ }^{1}$ Department of Internal Medicine, Utrecht University Hospital and \\ ${ }^{2}$ Department of Medical Pharmacology, Rudolf Magnus Institute, Utrecht University, The Netherlands
}

Summary. It has been shown that parameters of oxidative stress are increased in experimental diabetic neuropathy. The glutathione redox system is one of the intracellular scavenger systems for neutralizing free oxygen radicals. In this investigation we studied the effect of glutathione-treatment on the development of diabetic neuropathy in streptozotocin-induced diabetic rats by measuring sensory and motor nerve conduction velocities. The total study period was 10 weeks. Four groups of rats were studied: Group 1 consisted of non-diabetic, age-matched control rats; Group 2, of diabetic rats treated with placebo from week 0 to 10 ; Group 3, of diabetic rats treated with $200 \mathrm{mg}$ glutathione $/ \mathrm{kg}$ body weight i. v. two times per week from weeks 0 to 10 ; and Group 4, of diabetic rats treated with placebo from weeks 0 to 4 and as Group 3 from weeks 4 to 10 . The sensory and motor nerve conduction velocity of rats treated prophylac- tically with glutathione (Group 3) were significantly different from those of rats treated with placebo (Group 2) or with glutathione administered at a later time point (Group 4). Complete restoration of sensory and motor nerve conduction velocity was not reached. There was a significant improvement in motor nerve conduction velocity from weeks 4 to $6(p<0.005)$, but not in sensory nerve conduction velocity in the delayed treatment group (Group 4). In conclusion, treatment with glutathione, a free radical scavenger, is partially effective in the prevention of diabetic neuropathy in streptozotocin-induced diabetic rats, but is of limited value when the neuropathy is already present.

Key words: Diabetes mellitus, diabetic neuropathy, oxidative stress, glutathione, nerve conduction velocity, streptozotocin rat model.
Various mechanisms have been implicated in the pathogenesis of diabetic neuropathy in the streptozotocin (STZ)-induced diabetic rat. It has been shown that chronic hyperglycaemia leads to an increased activity of the polyol pathway and thus to sorbitol and fructose accumulation [1, 2]. Greene et al. [3] have shown that impaired motor nerve conduction velocity (MNCV) is linked to myo-inositol depletion in the STZ rat. The non-enzymatic glycation of myelin components in diabetic rats has been shown by Vlassara et al. [4, 5]. Tuck et al. [6] reported that endoneurial blood flow and oxygen tension are reduced in sciatic nerves of rats with experimental diabetic neuropathy (EDN). Low and co-workers [7] showed that some of the electrophysiological and biochemical abnormalities in EDN can be prevented by oxygen supplementation. They also showed that rats subjected to chronic hypoxia $(10 \%)$ developed electrophysiological abnormalities that were very similar to those of EDN, in the absence of hyperglycaemia, sorbitol accumulation, or myo-inositol reduction [8]. It is known that endoneurial hypoxia can lead to increased oxygen free radical activity and decreased forma- tion of lipid hydroperoxides [9]. Baynes recently reviewed the evidence [10] that oxidative stress plays a major role in the development of microangiopathic complications. Others have shown that glutathione (GSH) levels and superoxide dismutase activity are reduced in STZ-treated rats [11]. GSH reduces the deleterious effects of cell exposure to oxygen free radicals by reacting with peroxide to form glutathione disulphide (catalysed by glutathione peroxidase) and by promoting the synthesis of superoxide dismutase, another important scavenger $[11,12]$. We therefore explored the effect of GSH on both a developing and an existing neuropathy in the STZ-induced diabetic rat.

\section{Materials and methods}

\begin{abstract}
Animals
A total of 40 male rats of an inbred Wistar strain (CpB; Toegepast Natuur-wetenschappelijk Onderzoek, Zeist, The Netherlands), mean weight $250 \mathrm{~g}$, were used. The rats were kept in Macrolon cages with sawdust bedding (two rats per cage) and maintained on a 12:12 h light-dark cycle (lights on at 07.30 hours) with food and water
\end{abstract}




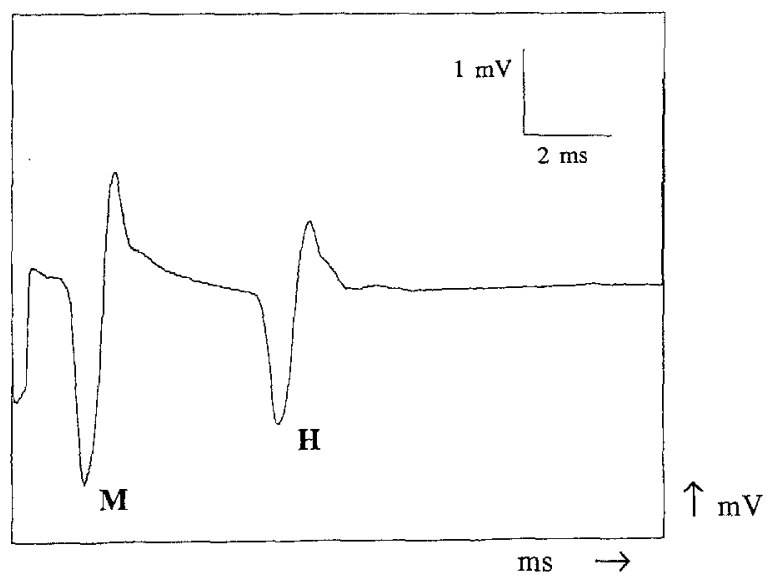

Fig. 1. A representative plot of an electromyograph response; the first deflection depicts a M-response and the second a H-response. Latency is measured in ms (horizontal axis) and amplitude in $\mathrm{mV}$ (vertical axis)

ad libitum. Diabetes was induced in 30 rats with a single $i$. v. injection of STZ (Zanosar; Upjohn Co., Kalamazoo, Mich., USA), $40 \mathrm{mg} / \mathrm{kg}$ body weight. Animals were considered to be diabetic when their blood glucose level was above $15 \mathrm{mmol} / \mathrm{l}, 48 \mathrm{~h}$ after the STZ injection. Glucose was measured with a Minilab (Bayer GmbH, München, FRG). At weeks $0,2,4,6,8$ and 10 sensory and motor nerve conduction velocities (SNCV and MNCV) were measured. Ten rats, designated as Group 1, were kept as non-diabetic, age-matched controls. The diabetic animals $(n=30)$ were randomly divided into three treatment groups: Group $2(n=10)$, in which animals were treated with placebo, $1 \mathrm{ml} 0.9 \% \mathrm{NaCl} / \mathrm{kg}$ body weight i.v. two times per week for 10 weeks; Group $3(n=9)$, in which animals were treated from weeks 0 to 10 with $200 \mathrm{mg}$ GSH/kg body weight dissolved in $0.9 \% \mathrm{NaCl}$ i.v. two times per week; and Group $4(n=11)$, in which animals were treated two times per week with $1 \mathrm{ml} 0.9 \%$ $\mathrm{NaCl} / \mathrm{kg}$ body weight from week 0 until week 4 and with $200 \mathrm{mg}$ GSH/kg body weight from week 4 to week 10 . At week 4 a neuropathy had already developed, as shown by a significant slowing of SNCV and MNCV. The investigator performing subsequent measurements was unaware of the sample identity.

\section{Drugs}

Glutathione (GSH) is a tri-peptide ( $\tau$-Glu-Cys-Gly) and was obtained from Boehringer Mannheim Italia (Monza, Italy) in sterile vials containing $2.5 \mathrm{~g}$ of lyophilized GSH. GSH was prepared fresh for each injection: it was diluted in $0.9 \% \mathrm{NaCl}(100 \mathrm{mg} / 1 \mathrm{ml})$ and was immediately injected $i$. v. into the lateral tail vein of a rat. Equivalent volumes of $0.9 \% \mathrm{NaCl}$ were injected in the animals of Group 2 and during the first 4 weeks in the animals of Group 4 . The dosage of $200 \mathrm{mg} / \mathrm{kg}$ body weight was chosen as a result of a GSH dose-finding study in rats with cisplatinin-induced neurotoxicity [Hamers and Gispen, unpublished data].

\section{Electrophysiology}

The electrophysiological examinations for determination of nerve conduction velocities were carried out under general anaesthesia (Hypnorm; Duphar, Weesp, The Netherlands, containing $10 \mathrm{mg} / \mathrm{ml}$ fluanisone and $0.2 \mathrm{mg} / \mathrm{ml}$ fentanyl citrate, at a dose of $0.8 \mathrm{mg} / \mathrm{kg}$ body weight, administered s.c.). To minimize effects of body temperature differences on conduction velocity, the animals were placed under a $40 \mathrm{~W}$ light bulb (at a distance of $25 \mathrm{~cm}$ ) 5 min prior to testing. During this procedure, the rectal temperature varied from 37 to $38^{\circ} \mathrm{C}$. The method used to measure the SNCV and MNCV has been described in detail by De Koning and Gispen [13]. The sciatic and
B. Bravenboer et al.: Glutathione and experimental diabetic neuropathy

tibial nerves were stimulated at the sciatic notch and ankle, respectively, by means of monopolar needle electrodes. The stimulus was a $500 \mu$ unipolar pulse, generated by a Neurolog NL 300 pulse generator. This stimulus was scaled by a Neurolog NL 510 pulse buffer and delivered by a Neurolog NL 800 stimulus isolator. The stimulation voltage was $42 \mathrm{~V}$; the current was between 1 and $10 \mathrm{~mA}$. The signal was recorded by surface electrodes (Nicolet, $1 \mathrm{~mm}$ diameter, silver $(20 \mathrm{~Hz}-10 \mathrm{kHz}$ ) and digitized (Gould Digital Storage Scope). The digitized signal was analysed with specially designed software (F.P.T. Hamers) on a personal computer. The anode was placed $5 \mathrm{~mm}$ proximal to the cathode. Upon stimulation of these mixed peripheral nerves, two responses were recorded from the small muscles of the foot by means of surface electrodes: the short-latency M-response, due to stimulation of $\alpha$-motor fibres, and the long-latency $\mathrm{H}$ response, due to stimulation of afferent la-fibres, which monosynaptically excite $\alpha$-motorneurons in the spinal cord $[13,14]$. From the latencies of these responses and the distance between the two stimulation points, $\mathrm{MNCV}$ and SNCV were calculated $[13,15]$. In Figure 1 a representative plot of an electromyograph response is shown.

\section{Statistical analysis}

Body weights and glucose levels are given as means \pm SD for the four different groups. Student Newman-Kuels' test was used to test for significant differences between groups. For SNCV and MNCV data are presented as means $\pm S E M$ in $\mathrm{m} / \mathrm{s}$ for the four different groups at weeks $0,2,4,6,8$ and 10. The treatment code for Groups 1 and 4 was partially broken at week 4 , but not to the investigators, to see if a significant neuropathy had developed. Student's $t$-test was used to compare Groups 1 and 4. A multivariate analysis of variance with repeated measurements was used to test for differences between Groups 2,3 and 4, to test for time trends and for an interaction between groups and time [16]. The two animals in Group 3, which died during the first two weeks of the study, were not included in the statistical analysis.

\section{Results}

\section{Weight and glucose levels}

Following the STZ-injection the glucose levels rose in all animals and remained stable throughout the entire study period. Furthermore, the three diabetic treatment groups did not differ significantly throughout the study: the mean glucose level of Group $2(n=10)$ was $24.9 \pm 5.1 \mathrm{mmol} / 1$, of Group $3(n=7) 24.6 \pm 3.2 \mathrm{mmol} / \mathrm{l}$ and of Group $4(n=10)$ $28.5 \pm 5.9 \mathrm{mmol} / 1$. During the 10 -week experimental period the increase in body weight of the three diabetic treatment groups was comparable, but lower than the weight gain in the non-diabetic control rats (Group 1) (Table 1). This difference was significant both at weeks 4 and 10 $(p<0.05)$.

Table 1. Body weight (g) of rats in the control group (Group 1) and in the streptozotocin-induced, diabetic groups treated with placebo (Group 2), glutathione from week 0 (Group 3) or from week 4 (Group 4)

\begin{tabular}{lllll}
\hline & & \multicolumn{3}{l}{ Week } \\
\cline { 3 - 5 } & $n$ & 0 & 4 & 10 \\
\hline Group 1 & 10 & $254.0 \pm 12.5$ & $356.5 \pm 30.6^{\mathrm{a}}$ & $429.8 \pm 37.2^{\mathrm{a}}$ \\
Group 2 & 10 & $257.4 \pm 8.0$ & $293.9 \pm 19.9$ & $306.2 \pm 26.6$ \\
Group 3 & 7 & $251.6 \pm 8.9$ & $289.4 \pm 22.8$ & $311.9 \pm 38.0$ \\
Group 4 & 11 & $250.5 \pm 4.0$ & $265.9 \pm 24.4$ & $263.9 \pm 43.8$ \\
\hline
\end{tabular}

a $p<0.05$, student Newman-Kuels' test when Group 1 is compared to Groups 2,3 and 4. Data are given as mean $\pm \mathrm{SD} ; n$ is the number of animals per group 


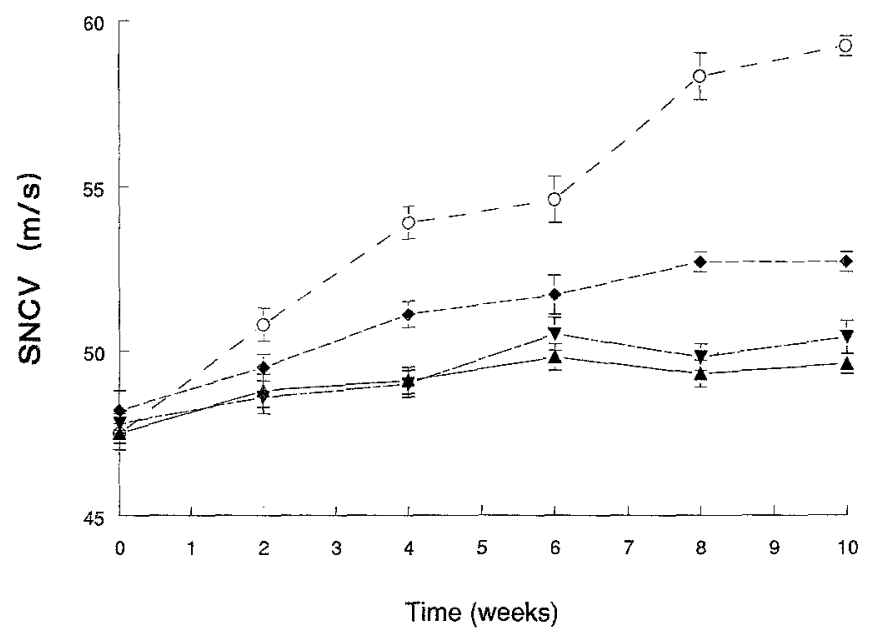

Fig. 2. Sensory nerve conduction velocity (SNCV) of Group 1, agematched control rats (O); Group 2, diabetic control rats (A); Group 3, rats treated with glutathione from week 0 to week $10(\bullet)$ and Group 4, rats treated with glutathione from week 4 to week $10(\nabla)$ shown as means \pm SEM at week $0,2,4,6,8$ and 10

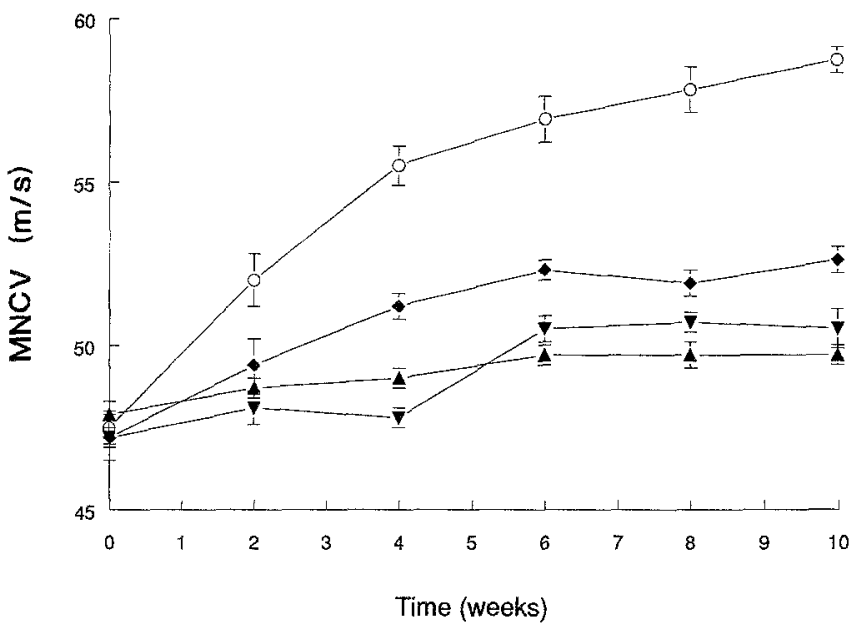

Fig. 3. Motor nerve conduction velocity (MNCV) of Group 1, agematched control rats (O); Group 2, diabetic control rats $(\mathbf{\Delta})$, Group 3, rats treated with glutathione from week 0 to week 10 ( ) and Group 4, rats treated with glutathione from week 4 to week $10(\boldsymbol{\nabla})$ shown as means \pm SEM at week $0,2,4,6,8$ and 10

\section{Nerve conduction velocity studies}

SNCV and MNCV data are presented in Figures 2 and 3. SNCV and MNCV increased considerably in the nondiabetic control rats, whereas the three diabetic groups showed a much smaller increase during the entire study period. There was no correlation between individual blood glucose levels and the individual values obtained for SNCV and MNCV. The non-diabetic controls (Group 1) showed an increase in SNCV from $47.5 \pm 0.5$ to $59.2 \pm 0.3 \mathrm{~m} / \mathrm{s}$ and in MNCV from $47.8 \pm 0.8$ to $57.1 \pm 0.3 \mathrm{~m} / \mathrm{s}$ from week 0 to 10 . Placebo-treated diabetic animals (Group 2) showed a slight increase in SNCV from $47.5 \pm 0.3$ to $49.8 \pm 0.4 \mathrm{~m} / \mathrm{s}$ during the first 6 weeks after which the SNCV stabilized. For MNCV there was an increase from $47.9 \pm 0.4$ to $49.7 \pm 0.3 \mathrm{~m} / \mathrm{s}$ during the first
6 weeks followed by a similar stabilization. The diabetic group treated with GSH from the beginning of the experiment (Group 3) showed a continued improvement in SNCV from week 0 to 10 , from $48.2 \pm 0.6$ to $52.7 \pm 0.2 \mathrm{~m} / \mathrm{s}$. MNCV improved from $47.3 \pm 0.6$ to $52.6 \pm 0.4 \mathrm{~m} / \mathrm{s}$ at week 10. In this group two animals died of respiratory tract infections unrelated to diabetes or testing. Group 4 (treated from week 4 with GSH) showed a small increase in SNCV from week 4 to week $10(49.0 \pm 0.4$ and $50.4 \pm 0.5 \mathrm{~m} / \mathrm{s}$, respectively). MNCV showed a similar increase from $47.8 \pm 0.3$ to $50.5 \pm 0.6 \mathrm{~m} / \mathrm{s}$ during the same time period. At week 4 there was a significant difference in SNCV and MNCV vs Group $1(p<0.001)$. The differences between Groups 2 and 4 with respect to SNCV and $\mathrm{MNCV}$ for the overall study period were not significant. However, the differences between the SNCV and MNCV values of Groups 2 and 3 were statistically significant $(p<0.001)$.

Analysis of the specific changes in SNCV and MNCV during certain time periods showed that, for SNCV, the difference in improvement between Group 3 and Groups 2 and 4 was significant from weeks 0 to 2 $(p=0.015)$ and from weeks 2 to $4(p=0.023)$. For MNCV, the difference in improvement between Group 3, and Groups 2 and 4 was only significant from weeks 0 to 2 $(p<0.005)$. There was also a significant difference in MNCV from week 4 (start of treatment) to week 6 , when the results of Group 4 were compared with those of Group $2(p<0.005)$. SNCV was not significantly different for any of the time periods studied when comparing Group 4 and 2.

\section{Discussion}

The present results indicate that GSH, a free radical scavenger, partially prevents the development of diabetic neuropathy in the STZ-induced diabetic rat. When treatment was started after 4 weeks, when there was already a slowing in nerve conduction velocity, there was some improvement in MNCV, but not in SNCV. One of the reasons for the lack of effect could be an insufficient weight gain in Group 4 or a more catabolic state, as suggested by somewhat higher glucose levels.

Antioxidant defense systems are present in all cells and play an important role in metabolism, transport and cellular protection [17]. GSH is involved in the glutathione redox cycle, which plays a role in protecting the sulphydryl group of cysteine in proteins and in other cell constituents. $\mathrm{GSH}$, together with superoxide dismutase and catalase, is important for the protection of cells against oxidation by free radicals and reactive oxygen intermediates $[17,18]$. GSH can be oxidized into glutathione disulphide (GSSG), which can be converted to GSH again by the enzyme glutathione reductase in a NADPH-dependent reaction [17,18].

It has been suggested that in the diabetic state glycoxidation products, formed by sequential glycation and oxidation reactions between reducing sugars and proteins, are involved in the pathogenesis of diabetic complications [10]. Auto-oxidation reactions of sugars moieties attached to proteins, together with auto-oxidation products of un- 
saturated lipids in plasma and membrane proteins, could lead to enhanced oxidative stress and further depletion of free radical scavenger systems and of free radical inhibitors [10, 18]. Morel et al. [19] have demonstrated that lipid peroxidation is increased, especially in the combined VLDL and LDL fractions, in rats with STZ-induced, poorly-controlled diabetes and hypertriglyceridaemia. Isolated VLDL is toxic to endothelial cells which may cause vascular changes impairing endoneurial blood flow resulting in chronic hypoxia.

Experimental studies have revealed that superoxide dismutase activity and GSH levels are decreased in STZtreated rats $[11,20]$. Low et al. [8] have reported that chronic hypoxia is involved in the pathogenesis of EDN, and have recently shown that endoneurial hypoxia can lead to increased free radical activity and decreased lipid hydroperoxides. They showed that superoxide dismutase activity is reduced in nerves of diabetic rats and levels of conjugated dienes are increased [9]. Aldose reductase, the first enzyme in the polyol pathway, also requires NADPH as a cofactor. It is possible that this competition for NADPH with GSSG-reductase hampers the ability of cells to scavenge oxidants due to insufficient GSH regeneration [20]. Another cause of the decreased levels of GSH could be reduced synthesis [21]. Superoxide dismutase and the GSH-redox cycle are the most important endogenous scavengers in nervous tissue [12]. Supplementation with GSH, as done in this experiment, could increase depleted GSH stores, which allows superoxide dismutase synthesis and thus correction of early metabolic abnormalities in EDN [11]. Comparison of our results with those obtained with other interventional therapies in EDN show that preventive treatment with GSH is less effective than, for example, the use of aldose reductase inhibitors. However, the dose of GSH used was perhaps insufficient owing to its short half-life. Greene et al. [2], using the same model, demonstrated that the near-normoglycaemia achieved by insulin treatment prevented the development of EDN and that oral supplementation of myo-inositol prevented the impairment of MNCV. Tomlinson et al. [22] have shown, that the impairment of MNCV and the defect of axonal transport can be prevented with the use of an aldose reductase inhibitor. In 1989 Van der Zee et al. [22] demonstrated that an $\mathrm{ACTH}^{4-9}$-analogue, ORG 2766 , provided full protection against the development of EDN in the STZ-model. Using the same model we have shown [24] that this neuropeptide is also effective in ameliorating existing neuropathy. Recently, Cameron et al. [25] showed that the use of evening primrose oil (Efamol) was effective in preventing the reduction in nerve conduction velocity and the increase in hypoxic resistance in STZ-induced, diabetic rats. They suggested that evening primrose oil might have an angiogenic effect. Sonobe et al. [26] demonstrated that the prostaglandin $\mathrm{E}_{1}$ analogue, OP-1206. $\alpha-\mathrm{CD}$, ameliorated the impairment of MNCV in diabetic rats and showed that this effect was related to an increased activity of $\mathrm{Na}, \mathrm{K}$, ATP-ase. Thus, the multitude of successful therapies suggests more than one pathogenetic mechanism is causing EDN. We conclude that treatment with GSH, a free radical scavenger, provides partial protection against the neuropathic effect of diabetes in the STZ rat model, even during persistent hyperglycaemia. Later stages of neuropathy were only minimally affected by GSH treatment, suggesting that oxidative stress is pathogenic in the initial stages of EDN. Further experiments are needed to determine the optimal dosage of GSH and to study the possibility of co-treatment with aldose reductase inhibitors and neuropeptides of the melanocortin family.

Acknowledgements. Special thanks go to Ms. I. van der Tweel of the Centre of Biostatistics, Utrecht, The Netherlands for her kind help with the statistics of this study and to Dr. E. Cavelletti, Boehringer Mannheim, Monza, Italy for the supply of glutathione.

\section{References}

1. Dyck PJ, James J, O'Brien PC (1987) Diagnosis, staging and classification of diabetic neuropathy and association with other complications. In: Dyck PJ, Thomas PK, Asbury AK, Winegrad AI, Porte D (eds) Diabetic neuropathy. WB Saunders Co., Philadelphia, pp 36-44

2. Greene DA, DeJesus PV Jr, Winegrad AI (1975) Effects of insulin and dietary myo-inositol on impaired peripheral motor nerve conduction velocity in acute streptozotocin diabetes. J Clin Invest 55: 1326-1336

3. Finegold D, Lattimer SA, Nolle S, Bernstein M, Greene DA (1983) Polyol pathway activity and myo-inositol metabolism: a suggested relationship in pathogenesis of diabetic neuropathy. Diabetes 32: 988-992

4. Vlassara H, Brownlee M, Cerami A (1983) Excessive non enzymatic glycosylation of peripheral and central nervous system myelin components in diabetic rats. Diabetes 32: 670-674

5. Vlassara H, Brownlee M, Cerami A (1985) Recognition and uptake of human diabetic peripheral nerve myelin by macrophages. Diabetes 34: 553-557

6. Tuck RR, Schmelzer JD, Low PA (1984) Endoneurial blood flow and oxygen tension in sciatic nerves of rats with experimental diabetic neuropathy. Brain 107: 935-950

7. Low PA, Tuck RR, Dyck PJ, Schmelzer JD, Yao JK (1984) Prevention of some electrophysiologic and biochemical abnormalities with oxygen-supplementation in experimental diabetic neuropathy. Proc Natl Acad Sci USA 81: 6894-6898

8. Low PA, Schmelzer JD, Ward KK, Yao JK (1986) Experimental chronic hypoxic neuropathy: relevance to diabetic neuropathy. Am J Physiol 250: E94-E99

9. Low PA, Nickander KK (1991) Oxygen free radical effects in sciatic nerve in experimental diabetes. Diabetes 40: 873-877

10. Baynes JW (1991) Role of oxidative stress in development of complications in diabetes. Diabetes 40: 405-412

11. Loven D, Schedl H, Wilson H et al. (1986) Effect of insulin and oral glutathione levels and superoxide dismutase activities in organs of rats with streptozotocin-induced diabetes. Diabetes 35 : $503-507$

12. Romero FJ, Segura-Aguilar J, Monsalve E et al. (1990) Antioxidant and glutathione-related enzymatic activities in rat sciatic nerve. Neurotoxicol Teratol 12: 603-605

13. De Koning P, Gispen WH (1987) Org 2766 improves functional and electrophysiological aspects of regenerating sciatic nerve in the rat. Peptides 8: 415-422

14. Waxman SG (1980) Determination of conduction velocity in myelinated nerve fibres. Muscle Nerve 3: 141-150

15. Stanley EF (1981) Sensory and motor nerve conduction velocities and the latency of the H-reflex during growth of the rat. Exp Neurol 71: 497-506

16. Fleiss JL (1986) The design and analysis of clinical experiments. John Wiley, Chichester, New York

17. Halliwell B, Gutteridge JMC (1989) Free radicals in biology and medicine, 2nd edn. Oxford University Press, Oxford 
18. Loven DP, Oberly $\mathbb{L W}(1989)$ Free radicals, insulin action, and diabetes. In: Superoxide dismutase. Pathological states. Oberly LW (ed) CRC Press, Boca Raton, pp 151-190

19. Morel DW, Chisolm GM (1989) Antioxidant treatment of diabetic rats inhibits lipoprotein oxidation and cytotoxicity. J Lipid Res 30: 1827-1834

20. Wohaieb SA, Godin V (1987) Alterations in free radical tissuedefense mechanisms in streptozotocin-induced diabetes in rat. Effects of insulin treatment. Diabetes 36: 1014-1018

21. Murakami K, Kondo T, Ohtsuka Y, Fujiwara Y, Shimada M, Kawakami Y (1989) Impairment of glutathione metabolism in erythrocytes from patients with diabetes mellitus. Metabolism 38: 753-758

22. Tomlinson DR, Moriarty RJ, Mayer JH (1984) Prevention and reversal of defective axonal transport and motor nerve conduction velocity in rats with experimental diabetes by treatment with the aldose reductase inhibitor sorbinil. Diabetes 33: $470-476$

23. Van der Zee CEEM, Gerritsen van der Hoop R, Gispen WH (1989) Beneficial effect of Org 2766 in treatment of peripheral neuropathy in streptozotocin-induced diabetic rats. Diabetes 38 : $225-230$
24. Bravenboer B, Kappelle AC, van Buren T, Erkelens DW, Gispen WH (1991) ACTH-analogue ORG 2766 can ameliorate existing neuropathy in diabetic rats. Diabetologia 34 [Suppl 2]: A 21 (Abstract)

25. Cameron NE, Cotter MA, Robertson S (1991) Essential fatty acid diet supplementation. Effects on peripheral nerve and skeletal muscle function and capillarization in streptozotocininduced diabetic rats. Diabetes 40: 532-539

26. Sonobe M, Yasuda H, Hisanaga T et al. (1991) Amelioration of nerve $\mathrm{Na}^{+}-\mathrm{K}^{+}$-ATPase activity independently of myo-inositol level by $\mathrm{PGE}_{1}$ analogue $\mathrm{OP}-1206 . \alpha-\mathrm{CD}$ in streptozotocininduced diabetic rats. Diabetes 40:726-730

Received: 11 March 1992

and in revised form: 14 May 1992

Prof. W. H. Gispen

Rudolf Magnus Institute

Vondellaan 6

NL-3521 GD Utrecht

The Netherlands 